\title{
Infecções nas gestantes e suas repercussões no concepto do instituto da mulher Dona Lindu na cidade de Manaus-AM
}

\section{Infections in pregnant women and their repercussions in the concept of the institute of the woman Dona Lindu in the city of Manaus-AM}

DOI: $10.46814 /$ lajdv2n6-021

Recebimento dos originais: 01/09/2020

Aceitação para publicação: 30/10/2020

\section{Maurício Diniz Santim}

pós-graduado em Perícias Médicas e Medicina Legal pela Faculdade de Ciências Medicas da Santa

Casa de Misericórdia de São Paulo.

Instituição de atuação atual: Faculdade de Ciências Medicas da Santa Casa de Misericórdia de São Paulo.

Endereço completo: Rua Paim, 296. Bela Vista. São Paulo - SP

E-mail: mauriciodiniz@me.com

Marianna Facchinetti Brock

doutora em Doenças Tropicais e Infecciosas pela Universidade do Estado do Amazonas Fundação de Medicina Tropical do Amazonas.

Universidade do Estado do Amazonas.

Av. Carvalho Leal, 1777 - Cachoeirinha, Manaus - AM

E-mail: mariannabrock@ hotmail.com

\section{Lorena Candido Brandão}

graduada em Medicina pela Universidade do Estado do Amazonas.

União Brasileira Beneficente - UBB

Alameda Santos 2387. Cerqueira César. São Paulo - SP

E-mail: lorenacbrandao@gmail.com

\section{Gabriela Diniz Santim}

graduada em Medicina pela Universidade do Estado do Amazonas.

Amil Assistência Médica Internacional.

Rua coriolano 710. Vila Romana. São Paulo - SP.

E-mail: gabrieladiniz27@gmail.com

\section{RESUMO}

A população materna é alvo de grande incidência de infecções com repercussões agudas e crônicas para o feto. O potencial de envolvimento fetal pode causar aborto, entre outras complicações. Muitas infecções são assintomáticas em adultos; acometendo gestantes, estas podem transmiti-las a seus filhos no decorrer da gravidez, no parto ou no aleitamento. Embora seja um tema recorrente, há uma escassez de estudos sobre as infecções na gestação na Região Norte, deixando lacunas no conhecimento sobre a realidade local. Dessa forma, o objetivo principal deste trabalho foi analisar as infecções maternas mais frequentes e suas repercussões no concepto no Instituto da Mulher Dona Lindu na cidade de Manaus-AM. O estudo abordou 374 parturientes e seus recém-nascidos. Para melhor analise, as pacientes foram divididas em dois: não infectadas e infectadas. No grupo das pacientes não infectadas, $48 \%$, a idade média foi de 25 ( \pm 6$)$ anos, $91 \%$ são pardas e $32 \%$ em união 
estável. O grupo das infectadas foi de $52 \%$, cuja principal infecção foi do trato urinário, atingindo 251 mulheres, cuja idade média foi de $24( \pm 7)$ anos, 79,6\% são pardas e 38\% eram solteiras. Em relação ao concepto, dentre as pacientes não infectadas, $2 \%$ foram pre-termos, $3 \%$ com baixo peso ao nascer com media de $2.850 \mathrm{~g}( \pm 250 \mathrm{~g})$, nenhum caso de má-formação congênita ou alterações fetais, $84 \%$ dos RN ficaram em alojamento conjunto (ALCON), contra os de mãe infectada, $3.190 \mathrm{~g}$ ( \pm $370 \mathrm{~g}$ ), desses, $92 \%$ à termo e $83 \%$ partos normais. $79 \%$ dos RN ficaram em ALCON, nenhum nasceu com má-formação ou patologias congênitas. Somente $17 \%$ apresentaram infecções ao nascer, tendo como causa principal bactérias $(48 \%)$.

Palavras-chave: Infecções, Puerpério, Gravidez, Amazonas, Manaus.

\section{ABSTRACT}

The maternal population is the target of a high incidence of infections with acute and chronic repercussions for the fetus. The potential for fetal involvement can cause miscarriage, among other complications. Many infections are asymptomatic in adults; affecting pregnant women, they can transmit them to their children during pregnancy, childbirth or breastfeeding. Although it is a recurring theme, there is a scarcity of studies on infections in pregnancy in the Northern Region, leaving gaps in knowledge about the local reality. Thus, the main objective of this work was to analyze the most frequent maternal infections and their repercussions on the conceptus at the Instituto da Mulher Dona Lindu in the city of Manaus-AM. The study covered 374 parturients and their newborns. For better analysis, the patients were divided into two: uninfected and infected. In the group of uninfected patients, $48 \%$, the mean age was $25( \pm 6)$ years, $91 \%$ are mixed race and $32 \%$ are in stable union. The group of those infected was $52 \%$, whose main infection was the urinary tract, reaching 251 women, whose average age was $24( \pm 7)$ years, $79.6 \%$ are mixed race and $38 \%$ were single. Regarding the conceptus, among the uninfected patients, $2 \%$ were preterm, $3 \%$ with low birth weight with an average of $2,850 \mathrm{~g}( \pm 250 \mathrm{~g})$, no case of congenital malformation or fetal changes, $84 \%$ of NB stayed in joint housing (ALCON), against those of an infected mother, 3,190 g ( $\pm 370 \mathrm{~g})$, of which $92 \%$ at term and $83 \%$ normal births. $79 \%$ of newborns stayed in ALCON, none were born with malformations or congenital pathologies. Only $17 \%$ had infections at birth, with bacteria as the main cause $(48 \%)$.

Keywords: Infections, Puerperium, Pregnancy, Amazonas, Manaus.

\section{INTRODUÇÃO}

Cerca de $10 \%$ de todos os nascidos vivos são afetados pelas infecções congênitas e perinatais. A população materna é alvo de grande incidência de infecções com repercussões agudas e crônicas para o feto, evidenciando a relevância da avaliação do grau de comprometimento dessas mulheres. O tratamento da doença da mãe, o efeito da infecção na gravidez e a influência sobre o feto da doença materna e da terapêutica utilizada estão essencialmente envolvidos nesse processo.

O potencial de envolvimento fetal pode causar aborto, malformação congênita, atraso de crescimento intra-uterino, rotura prematura de membranas, parto pré-termo e infecção neonatal. (MS, Lisboa, 2000) 
O Vírus da Imunodeficiência Humana, o Vírus da Hepatite B, o Treponema pallidum, o Toxoplasma gondii e os diversos causadores de Infecção do Trato Urinário são agentes importantes causadores dessas doenças. Sua transmissão pode ser vertical e, nesse caso, ocorrer durante a gestação, no momento do parto ou durante o aleitamento materno. (FIGUEIRO-FILHO, E. A., et al, 2007)

Doenças infecciosas durante o referido período são relativamente frequentes no Brasil, especialmente em populações menos favorecidas. Dessa forma, o conhecimento das principais doenças infecciosas em gestantes e suas repercussões no concepto de forma prática e abrangente tem grande importância na formulação de políticas de saúde que reduzirão a morbimortalidade materno-fetal, melhorando os indicadores de saúde de uma determinada região (FIGUEIROFILHO, E. A., et al, 2007).

Compreende-se que há grande probabilidade de transmissão vertical do HIV, sendo evidenciado que a maioria dos casos de transmissão ocorre durante o trabalho de parto e no parto propriamente dito. Os casos de AIDS em crianças menores de 13 anos têm quase que a totalidade de casos como fonte de infecção a transmissão vertical (LEMOS, L. M. D.; GURGEL, R. Q.; FABBRO, A. L . D., 2005).

Vários fatores tornam a infecção do trato urinário (ITU) uma relevante complicação do período gestacional, agravando tanto o prognóstico materno quanto o perinatal. Preocupação adicional para os profissionais responsáveis pela atenção pré-natal destas mulheres é que, além da incidência aumentada de infecções sintomáticas entre grávidas, justamente neste período, o arsenal terapêutico antimicrobiano e as possibilidades profiláticas são restritos, considerando-se a toxicidade de alguns fármacos para o feto. Por estes motivos, o conjunto do diagnóstico precoce, seguido de terapêutica adequada e imediata, é imprescindível durante a assistência pré-natal, evitando comprometer o prognóstico materno e gestacional (DUARTE, G.; MARCOLIN, A. C.; QUINTANA, S. M.; CAVALLI, R. C., 2008).

A sífilis que tem como agente etiológico o Treponema pallidum, ainda constitui uma doença com sérias implicações para a mulher grávida e sua prole, podendo causar abortamento, morte intrauterina, óbito neonatal ou deixar sequelas graves nos recém-nascidos (FIGUEIROFILHO, E. A., et al, 2007).

Os riscos estimados de desenvolvimento de hidrocefalia, coriorretinite e calcificação intracraniana isolada são de $61 \%$ quando a infecção ocorre até a $13^{\mathrm{a}}$ semana, risco de $25 \%$ quando ocorre até a $26^{\mathrm{a}}$ semana e de $9 \%$ quando ocorre até a $36^{\mathrm{a}}$ semana. Muitos recém-nascidos assintomáticos apresentarão lesões oculares ou de sistema nervoso central que podem ser evitadas 
ou minimizadas com tratamento precoce. (REIS, M. M.; TESSARO, M. M.; D’AZEVEDO, P. A., 2006).

O vírus da hepatite B é a principal causa de hepatopatia crônica no mundo. Muitos estudos demonstram que a imunoprofilaxia imediatamente após o nascimento, com a administração da vacina e imunoglobulina, previne a infecção neonatal pelo VHB em mais de $90 \%$ dos casos. A transmissão vertical é responsável por 35 a $40 \%$ dos novos casos de hepatite B no mundo e é por meio dela que o vírus é mantido na população. (FIGUEIRO-FILHO, E. A., et al, 2007).

\section{JUSTIFICATIVA}

Embora existam diversos estudos sobre as infecções na gestação, desenvolvidos em outras regiões do país, há poucos relatos sobre a realidade da Região Norte, existindo lacunas do conhecimento, particularmente no Estado do Amazonas. Dessa forma, o interesse principal deste trabalho foi avaliar as infecções mais frequentes na gestação e suas repercussões no concepto, bem como dados epidemiológicos correlacionados a essas infecções. Objetivando subsidiar a tomada de decisão em Saúde Pública, relativos ao planejamento de programas de prevenção e assistência.

\section{OBJETIVOS}

\subsection{GERAL}

Analisar as infecções maternas mais frequentes e suas repercussões no concepto no Instituto da Mulher Dona Lindu na cidade de Manaus- AM.

\subsection{ESPECÍFICOS}

a) Analisar a relação entre infecção materna e as prováveis alterações no concepto.

b) Analisar as repercussões em conceptos infectados verticalmente pelo vírus da imunodeficiência humana, vírus da hepatite B, Treponema pallidum, Toxoplasma gondii e agentes etiológicos de infecção do trato urinário.

Correlacionar as infecções referidas com os dados epidemiológicos da gestante e do concepto.

\section{REVISÃO DE LITERATURA}

O conhecimento da incidência, da etiologia, da patogênese, do diagnóstico e do manejo de infecções na gestação, no parto e no período neonatal é relevante, pois, podem ocorrer prejuízos para o concepto, tanto aguda quanto cronicamente, mesmo se não expressos no momento do nascimento (MUSSI-PINHATA, M. M.; YAMAMOTO, A. Y., 1999). 
Segundo o Ministério da Saúde (2007), a transmissão vertical do HIV ocorre através da passagem do vírus da mãe para o bebê durante a gestação, o trabalho de parto, o parto propriamente dito (contato com as secreções cérvico-vaginais e sangue materno) ou a amamentação, sendo que cerca de 35\% dessa transmissão ocorre durante a gestação, $65 \%$ ocorre no peri-parto e há um risco acrescido de transmissão através da amamentação entre $7 \%$ e $22 \%$ por exposição. Com uma prevalência de $0,41 \%$ de infecção pelo HIV em gestantes, estima-se que 12.456 recém-nascidos sejam expostos ao HIV por ano.

Aos 12 meses de idade, cerca de 50\% das crianças infectadas pelo HIV desenvolvem supressão imunológica moderada, enquanto $20 \%$ desenvolvem supressão imunológica severa. O risco de progressão rápida da doença é menor em crianças com mais de 1 ano. Está claro que as crianças com AIDS clínica ou imunossupressão grave estão em risco para o avanço da doença e morte. (OLESKE, 2006).

Embora não se disponha de estudos sobre as formas de transmissão predominantes na região amazônica, estima-se que a transmissão mãe-filho possa contribuir para a manutenção dessa endemia. A transmissão perinatal representa uma das vias mais eficazes de transmissão, e a que mais frequentemente leva a sequelas. Recém-nascidos infectados evoluem para cronicidade em cerca de 80 a $90 \%$ dos casos, condição fortemente associada ao posterior desenvolvimento de hepatite crônica, cirrose hepática e carcinoma hepatocelular (KIESSLICH et al, 2003).

Geralmente, a infectividade materna é avaliada segundo a reatividade ao antígeno "e" do VHB (HBeAg), uma vez que, na sua presença, a taxa de transmissão perinatal pode ser superior a $70 \%$, quando não se utiliza a imunoprofilaxia específica. Do ponto de vista da transmissão mãefilho, os níveis de VHB-DNA maternos podem predizer melhor o risco de infecção, bem como a evolução crônica em recém-nascidos infectados, quando comparados à reatividade ao $\mathrm{HBe} \mathrm{Ag}$ (KIESSLICH et al, 2003).

O Protocolo de Prevenção à Transmissão Vertical HIV/Sífilis (2007) define sífilis congênita como o resultado da disseminação hematogênica do Treponema pallidum da gestante infectada, não tratada ou inadequadamente tratada, para o seu concepto por via transplacentária. Conforme Chequer (DIAGNÓSTICO, 2004), aproximadamente $60 \mathrm{mil}$ ou 1,7\% das mulheres grávidas brasileiras são portadoras da infecção, entre elas, $70 \%$ transmitem a doença aos bebês. A sífilis pode trazer sérios problemas à saúde da criança e causar até mesmo o aborto. A infecção fetal poderia ser atenuada ou prevenida quando há tratamento materno após um diagnóstico precoce. De acordo com Silvia et al. (2003) o parasita atinge o concepto por via transplacentária causando danos de diferentes graus de gravidade, dependendo da virulência da cepa do parasita, da 
capacidade da resposta imune da mãe e do período gestacional em que a mulher se encontra, podendo resultar, inclusive, em morte fetal ou em graves manifestações clínicas.

Em diferentes países, a frequência de aquisição de toxoplasmose durante a gravidez varia de 1 a 14 casos por 1.000 gestações; no entanto, a infecção congênita ocorre em 0,2 a 2 recémnascidos por 1.000 nascimentos. A toxoplasmose pode passar despercebida no momento do nascimento, porém poderá se manifestar meses ou até anos depois. Nesses casos, as manifestações mais frequentes são retinocoroidite e alterações neurológicas. Nos casos mais graves de infecção congênita, o recém-nascido pode apresentar modificação do volume craniano, calcificações intracerebrais e/ou convulsões. No soro do recém-nascido, a presença de títulos elevados de anticorpos IgG, que aumentam ou permanecem positivos em período de até 18 meses, é indicativo de toxoplasmose congênita. (SPALDING et al, 2003).

Infecções do trato urinário (ITU) representam a infecção bacteriana mais comum na gestação. Na maioria das pacientes a infecção parece estar confinada ao trato urinário baixo. A bacteriúria assintomática no primeiro trimestre da gestação apresenta uma prevalência em torno de $5 \%$ a $10 \%$ das gestantes, quando não tratada, pode evoluir para cistite sintomática em aproximadamente $30 \%$ das gestantes e pode levar ao desenvolvimento de pielonefrite em até $50 \%$ delas. Cistite é a infecção que compromete a bexiga urinária, incidindo em cerca de $1 \%$ a 1,5\% das gestantes. A maioria das pacientes que desenvolve cistite apresenta culturas negativas no início da gestação. Pielonefrite ocorre em $1 \%$ a $2 \%$ das gestantes e pode resultar em significante morbidade materna, assim como morbidade e mortalidade fetal. A ITU está associada a complicações para o binômio materno-fetal, onde se destacam o trabalho de parto e parto prematuro, ruptura prematura de membranas amnióticas, restrição de crescimento intraútero, paralisia cerebral/retardo mental e óbito perinatal. A proporção de complicações diminui através de investigação e tratamento adequados (SALCEDO et al, 2010).

\section{TRAJETÓRIA METODOLÓGICA}

\subsection{TIPO DE ESTUDO}

Trata-se de um estudo epidemiológico descritivo, transversal.

\subsection{LOCAL DE ESTUDO}

A pesquisa será realizada no Instituto da Mulher Dona Lindu localizado na Rua Recife, nº 1580, no Bairro Adrianopolis, Manaus - AM. 


\subsection{POPULAÇÃO E AMOSTRA}

A população do estudo será constituída por 1280 puérperas. Segue o cálculo para o tamanho de amostra:

A amostra será calculada com uma margem de erro igual a cinco por cento (5\%), ou seja, com índice de confiabilidade de noventa e cinco (95\%), utilizando-se as fórmulas estatísticas, preconizada Barbetta (2002):

- $\quad N=$ Tamanho da população

- $\boldsymbol{E}_{\boldsymbol{0}}=$ Erro amostral tolerável

- $\quad \boldsymbol{n 0}=$ Primeira aproximação do tamanho da amostra

- $\quad \boldsymbol{n}=$ Tamanho da amostra

$\mathrm{N}=\mathbf{1 2 8 0}$

$n_{0}=400$

$\mathrm{E}_{0}=\mathbf{5 \%}$

$\mathbf{n}=\mathbf{3 5 0}$

\section{Cálculo:}

Primeiramente foi calculada a primeira aproximação à amostra $\left(n_{0}\right)$, utilizando-se a formula abaixo, sendo "1" uma constante.

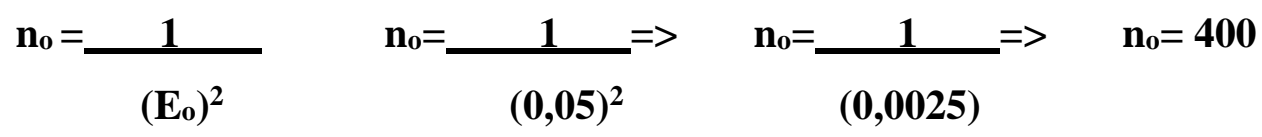

Em seguida calculou-se o tamanho da amostra:

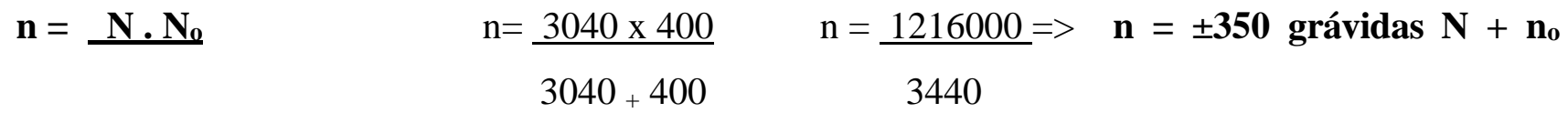

O tamanho mínimo da amostra a ser pesquisada será de $\mathbf{3 5 0}$ grávidas.

Para seleção da amostra serão observados os seguintes critérios de inclusão:

- Pacientes do sexo feminino com betaHCG positivo;

- Residente no município de Manaus-Amazonas;

- Receber assistência de saúde no âmbito do Sistema Único de Saúde (SUS);

- Aceitar voluntariamente participar do estudo, assinando o TCLE (Apêndice A). 


\subsection{INSTRUMENTO DE COLETA DE DADOS}

Os dados serão obtidos através de um questionário contendo questões fechadas, elaboradas pelo próprio pesquisador.

\subsection{PROCEDIMENTO PARA COLETA E ANÁLISE DE DADOS}

A pesquisa será desenvolvida nas seguintes etapas:

- Identificação dos sujeitos da pesquisa;

- Leitura conjunta do TCLE e assinatura dos participantes;

- Aplicação do questionário;

- Após a coleta de todos os dados, será constituído um banco com os dados quantitativos, para ser submetido à tratamento estatístico nos programas Epi-Info, Harvard Graphics e outros, serão analisados e discutidos à luz do referencial teórico que fundamenta o estudo, apresentados em forma de tabelas, gráficos e quadros.

\subsection{CONSIDERAÇÕES ÉTICAS}

Por se tratar de estudo envolvendo seres humanos, a pesquisa será submetida ao Comitê de Ética em Pesquisa - CEP da Universidade do Estado do Amazonas - ESA/UEA, em cumprimento à Res. CONEP N 196/96, e a coleta de dados será iniciada após a aprovação do estudo.

\section{REFERÊNCIAS}

BRASIL. Ministério da Saúde. Protocolo para a prevenção de transmissão vertical de HIV e sífilis. 1.ed. Brasília, 2007.

DUARTE, G. et al. Infecção urinária na gravidez. Revista Brasileira de Ginecologia e Obstetrícia. vol. 30. n.

2. pág.: 93-100, 2008. Disponível em <http://www.scielo.br/pdf/rbgo/v30n2/08.pdf>. Acesso em: 13.Abr. 2014.

FIGUEIRÓ-FILHO, E. A. et al. Freqüência das infecções pelo HIV-1, rubéola, sífilis, toxoplasmose, citomegalovírus, herpes simples, hepatite $\mathrm{B}$, hepatite $\mathrm{C}$, doença de Chagas e HTLV I/II em gestantes, do Estado de Mato Grosso do Sul. Revista da Sociedade Brasileira de Medicina Tropical. vol. 40. n. 2. pág.: 181-187, 2007. Disponível em: 〈http://www.scielo.br/pdf/rsbmt/v40n2/a07v40n2.pdf>. Acesso em: 13.Abr. 2014.

KIESSLICH, D. et al. Prevalência de marcadores sorológicos e moleculares do vírus da hepatite B em gestantes do Estado do Amazonas, Brasil. Epidemiologia e Serviços de Saúde. vol. 12 n. 3. pág.: $\quad 155 \quad-\quad$ 164, $2003 . \quad$ Disponível 
<http://iah.iec.pa.gov.br/iah/fulltext/pc/portal/ess/v12n3/pdf/v12n3a06.pdf>. Acesso em: 13.Abr. 2014.

LEMOS, L. M. D.; GURGEL, R. Q.; FABBRO, A. L. D. Prevalência da infecção por HIV em parturientes de maternidades vinculadas ao SUS. Revista Brasileira de Ginecologia e Obstetrícia. vol. 27. n. 1. pág.: 32-6, 2005. Disponível em: 〈http://www.scielo.br/pdf/rbgo/v27n1/24289.pdf>. Acesso em: 13.Abr. 2014.

MUSSI-PINHATA, M.M.; YAMAMOTO, A. Y. Infecções congênitas e perinatais. Jornal de Pediatria. vol.

75. supl.1, 1999. Disponível em: < http://www.jped.com.br/conteudo/99-75-S15/port.pdf>. Acesso em: 13.Abr.2014.

OLESKE, J. M. Quando tratar as crianças com HIV?. Jornal de Pediatria. vol. 82. n.4, 2006. Disponível em:

< http://www.scielo.br/pdf/jped/v82n4/v82n4a02.pdf>. Acesso em: 13.Abr. 2014.

REICHE, E. M. V. Et al. Prevalência de tripanossomíase americana, sífilis, toxoplasmose, rubéola, hepatite $\mathrm{B}$, hepatite $\mathrm{C}$ e da infecção pelo vírus da imunodeficiência humana, avaliada por intermédio de testes sorológicos, em gestantes atendidas no período de 1996 a 1998 no Hospital Universitário Regional Norte do Paraná (Universidade Estadual de Londrina, Paraná, Brasil). Revista da Sociedade Brasileira de Medicina Tropical. vol. 33. n. 6. pág.: 519-527, 2000. Disponível em: $<$ http://www.scielo.br/pdf/rsbmt/v33n6/3641.pdf >. Acesso

em: 13.Abr. 2014.

REIS, M. M.; TESSARO, M. M.; AZEVEDO, P.A. Perfil sorológico para toxoplasmose em gestantes de um hospital público de Porto Alegre. Revista Brasileira de Ginecologia e Obstetricia. vol. 28. n.3. pág.: 158-64, 2006. Disponível em: 〈http://www.scielo.br/pdf/rbgo/v28n3/30841.pdf〉. Acesso em: 13.Abr. 2014.

SALCEDO, M. M. B. P. et al. Infecção urinária na gestação. RBM Pediatria Moderna. vol. 67. n. 8, 2010. Disponível em: <http://www.moreirajr.com.br/revistas.asp?fase=r003\&id_materia=4377>. Acesso em: 13.Abr. 2014.

SPALDING, S. M. et al. Estudo prospectivo de gestantes e seus bebês com risco de transmissão de toxoplasmose congênita em município do Rio Grande do Sul. Revista da Sociedade Brasileira de Medicina Tropical. vol. 36. n. 4. pág.: 483-491, 2003. Disponível em <http://www.scielo.br/pdf/rsbmt/v36n4/16727.pdf>. Acesso em: 13.Abr. 2014. 


\section{APÊNDICES}

\section{Apêndice A}

\section{TERMO DE CONSENTIMENTO LIVRE E ESCLARECIDO - TCLE}

(Preencher duas cópias: Uma fica com o sujeito da pesquisa e outra com o pesquisador, para arquivamento)

Você está sendo convidada a participar deste estudo intitulado "INFECÇÕES NAS GESTANTES E SUAS REPERCUSSÕES NO CONCEPTO DO INSTITUTO DA MULHER DONA LINDU NA CIDADE DE MANAUS- AM" porque você tem perfil e preenche os critérios para, na condição de sujeito, participar desta pesquisa. Sujeito da pesquisa é a expressão dada a todo ser humano que, de livre e espontânea vontade e após devidamente esclarecido, concorda em participar de pesquisa, doando material biológico, se submetendo a variados procedimentos invasivos ou não, ou ainda fornecendo informações.

Neste estudo, você será submetida a uma entrevista com o objetivo de fornecer informações para o melhor entendimento do assunto em questão, e você terá toda autonomia para decidir entrar ou não na pesquisa. Também, você terá toda liberdade para se retirar do estudo a qualquer momento, sem prejuízo de qualquer natureza. Tanto sua pessoa quanto os dados por você fornecidos serão mantidos sob absoluta confidencialidade e, portanto, ninguém mais terá conhecimento sobre sua participação.

Embora a natureza desta pesquisa apresente risco muito baixo, você tem a garantia de indenização por parte da Instituição promotora da pesquisa e do investigador, se acontecer dano(s) à sua saúde, em decorrência da pesquisa; e sua decisão de participar do estudo não está de maneira alguma associada a qualquer tipo de recompensa financeira ou em outra espécie.

Deve ser rubricado em todas as suas páginas e assinado, ao seu término, pelo voluntário participante da pesquisa ou por seus responsáveis legais e pelo pesquisador responsável, ou seus representantes nomeados, não devendo as páginas de assinaturas constituírem um documento separado.

Sempre que for necessário esclarecer alguma dúvida sobre o estudo, você deverá buscar contato com o Coordenador da Pesquisa Prof.. Msc. Marianna Facchinetti Brock, no endereço ou no telefone, ou por intermédio do Aluno Mauricio Diniz Santim no endereço Av. Efigênio Sales, 2055. Casa 126. Aleixo. Manaus - AM ou no telefone 9208-4006. Para quaisquer informações, fica disponibilizado o endereço do CEP da Universidade do Estado do Amazonas à Av. Carvalho Leal, 1777 - Escola Superior de Ciências da Saúde, $1^{\text {o }}$ andar, Cachoeirinha - CEP 69065-001, Fone 38784368, Manaus-AM. 


\section{O N S E N T I M E N T O}

$\mathrm{Li}$, tomei conhecimento, entendi os aspectos da pesquisa e, voluntariamente, concordo em participar do estudo.

\section{Assinatura do sujeito da pesquisa}

Residência:

Fone(s):

Manaus, de de 20

\section{Apêndice B}

QUESTIONÁRIO: LEITO: DATA: 1

\section{DADOS DA MÃE:}

INICIAIS:

IDADE:

ESCOLARIDADE: ( ) NENHUMA ( ) FUNDAMENTAL ( ) MÉDIO ( ) SUPERIOR ESTADO CIVIL: ( ) CASADA ( ) UNIÃO ESTÁVEL ( ) SOLTEIRA ( ) VIÚVA RAÇA: ( ) BRANCA ( ) NEGRA ( ) PARDA ( ) INDÍGENA

PROFISSÃO: ( ) DO LAR ( ) DOMÉSTICA ( ) DISTRITO ( ) COMÉRCIO ( ) ESTUDANTE ( ) OUTROS NATURALIDADE:

RESIDÊNCIA:

ZONAS: ( ) NORTE ( ) SUL ( ) LESTE ( ) OESTE ( ) CENTRO-SUL ( ) CENTRO-OESTE ( ) FORA DE MANAUS

GESTA: PARA: ABORTO: PROVOCADO / ESPONTÂNEO)

PATOLOGIAS PRÉVIAS À GESTAÇÃO: ( ) HAS ( ) DM ( ) CARDIOPATIA ( ) CIRURGIAS UTERINAS PRÉVIAS ( ) MÁ FORMAÇÃ̃ ( ) ITU ( ) OUTROS

PESO: INÍCIO DO PRÉ-NATAL Kg FIM DO PRÉ-NATAL Kg MÉDIA: 
INTERCORRÊNCIAS NA GESTAÇÃO:

( ) HAS ( ) DM ( ) AMNIORREXE ( ) ITU DE REPETIÇÃO ( ) OUTRAS

EXAMES LABORATORIAIS : ( ) COMPLETO ( ) INCOMPLETO ( ) NÃO FEZ EXAMES DE ULTRASSONOGRAFIA : ( ) NENHUM ( ) 1 ( ) 2 ( ) 3 ( ) + de 3 MORFOLÓGICO: ( ) SIM ( ) NÃO DOPPLER: ( ) SIM ( ) NÃO

ALTERAÇÃO FETAL PRÉ-NATAL? ( ) SIM ( ) NÃO

COLPOCITOLOGIA: ( ) SIM ( ) NÃO ( ) JÁ TINHA FEITO HÁ MENOS DE 01 ANO

( ) INFLAMATÓRIO ( ) VAGINOSE ( ) TRICHOMONAS ( ) CÂNDIDA ( ) HPV ( ) NIC I ( ) NIC II ( ) NIC III ( ) CA

FEZ USO DE ALGUMA MEDICAÇÃO NO PRÉ-NATAL?

( ) SULFATO FERROSO ( ) ÁCIDO FÓLICO ( ) VITAMINAS

( ) ANTI HIPERTENSIVOS ( ) ANTIBIÓTICOS ( ) INSULINA ( ) OUTROS:

\section{DADOS DO NEONATO:}

IDADE GESTACIONAL CAPURRO: SEXO: ( ) F ( ) M PESO: ( ) PARTO PREMATURO ( ) A TERMO

APGAR DE NASCIMENTO EM 5 MIN: PARTO: ( ) CESÁREA ( ) NORMAL RN FICOU EM: ( ) UTI ( ) ALCON MÁ FORMAÇÃO: ( ) SIM ( ) NÃO PATOLOGIA CONGÊNITA: ( ) SIM ( ) NÃO INFECÇÃO NEONATAL: ( ) SIM ( ) NÃO ( ) ITU ( ) SÍFILIS ( ) HIV ( ) BACTERIANA ( )FÚNGICA ( ) OUTROS: 